\title{
Study on Influence of Aggregate Combination and Inhibition Material of Alkali- silica Reaction in Fully-Graded Concrete
}

\author{
Huaquan YANG ${ }^{1}$, Zhen LI ${ }^{1}$, Meijuan $\mathrm{RAO}^{2 *}$, Xiaomei SHAO ${ }^{1}$ \\ ${ }^{1}$ Changjiang River Scientific Research Institute Wuhan, P.R.China \\ ${ }^{2}$ State Key Laboratory of Silicate Materials for Architectures, Wuhan University of Technology, Wuhan, 430070, China \\ crossref http://dx.doi.org/10.5755/j01.ms.26.3.19451
}

Received 21 August 2018; accepted 01 February 2019

\begin{abstract}
The influences of aggregate combination and inhibitor additives on the Alkali-silica Reaction (ASR) were studied in this research. A long-term alkali activity simulation of fully-graded concrete also was carried out. The results showed that replacement of artificial sandstone sand with artificial marble sand reduced the alkali activity expansion rate of the sandstone aggregate and effectively improved the inhibition effect of the aggregate when mixed with $35 \%$ fly ash. Activated silica in the fly ash was crushed into particles and was mixed into each part of the concrete system. It transformed the limited parts into unlimited active centers. As a result, each center participated in the reaction and consumed the alkali. Inhibition of the ASR was effective when the fly-ash content of the ASR-1 was $15 \%$, while in the ASR-2, the fly-ash did not have a significant inhibition effect. During a long-term simulation, the expansion rate of theconcrete specimens after standard curing at $20^{\circ} \mathrm{C}$ was higher than was the expansion rate after outdoor natural curing. The expansion rate of full sandstone concrete specimens was higher than was that of sandstone specimens that contained marble stone.

Keywords: aggregate combination, ASR, fully-graded concrete.
\end{abstract}

\section{INTRODUCTION}

The Alkali-silica Reaction (ASR) is one of the most important factors affecting the durability of concrete [1]. The alkali in concrete can react with the active silicon oxide in the aggregate and the reaction products may exhibit water swelling. This can generate internal pressure, resulting in cracking, loss of designed performance and, ultimately, structural damage. Alkali-aggregate reactions can cause serious damage to the durability and safe operation of concrete structures $[2,3]$.

The mechanism of ASR is complicated and there have been differences in opinion about it amongst researchers. According to Lee [4], the reactive silica in aggregate is depolymerized in a highly alkaline condition. Hydrolysis of silica takes place in the presence of sodium and potassium hydroxides and an alkali silicate gel is formed. This gel absorbs a large quantity of water from the surroundings, resulting in an expansion of its volume. Expansion of the alkali-silica gel causes micro-cracking, both inside the aggregate and at the interface between the aggregate and the cement paste [5-11]. The presence of a higher percentage of calcite also was found to cause greater expansion of concrete.

An alkali-aggregate reaction is a relatively slow process, ranging in duration from a few years to multiple decades. The reaction may take even longer for slowly inflating reactive aggregates with low activity. Water conservation and hydropower projects can have service lives of up to one hundred years. Combined with the humid condition of the concrete, this can provide a suitable environment for alkali-aggregate reactions [12-15]. Once the alkali-aggregate reaction occurs, it is difficult to stop and/or repair retroactively. Thus, the prevention and control of these concrete alkali-aggregate reactions has been the focus of a large number of research studies. Current control measures of alkali-aggregate reactions mainly include the use of non-active aggregates, total alkali content controlof the concrete, humidity control, and the incorporation of suppressing materials and chemical admixtures [16], amongst others.

Aggregate is an important component of concrete which act sas rigid skeleton. With the development of modern concrete technology, researchers have realized that aggregate has decisive influence on many important characteristics of concrete especially in fully-graded concrete (size ranges $5 \sim 20 \mathrm{~mm}, 20 \sim 40 \mathrm{~mm}, 40 \sim 80 \mathrm{~mm}$, $80 \sim 120 \mathrm{~mm}$ ) $[17,18]$. Based on the former researches, different combinations of aggregates were selected and their alkali-aggregate reactions under various conditions were evaluated in this present investigation. An alkali activitysuppressing material also was applied to inhibit the alkali activity of the sandstone. The effectiveness of this material was evaluated with a fully-graded aggregate concrete longterm aging test. SEM examination was used during the concrete alkali active long-term aging tests to understand qualitatively the alkali activity reaction degree and to predict the deterioration trend of the concrete.

\section{EXPERIMENTAL}

\subsection{Raw materials}

42.5 moderate-heat cements were used in this study. $\mathrm{NaOH}$ was added to the cement, which increased the alkali content of the cement to $1.25 \%$ in order to accelerate the

*Corresponding author. Tel.: +86-13607122449; fax: +86-02787651771.

E-mail address: raomeijuanding@163.com (M. Rao) 
ASR reaction. The ASR-restraining materials were metakaolin calcined at different temperatures, and speciallydesigned combined materials (composited powder). Table 1 shows the chemical properties of the cement, the ASRrestrain materials, the fly ash and the aggregates. Sandstone and marble aggregate were chosen for this work. SEM images and X-ray diffraction plots are shown in Fig. 1 and Fig. 2.

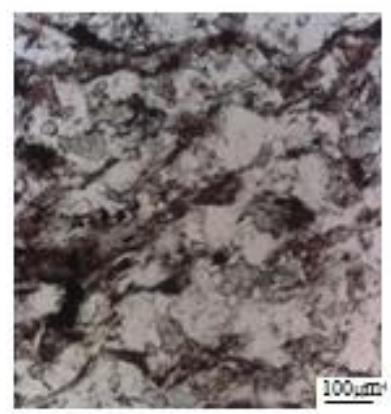

a

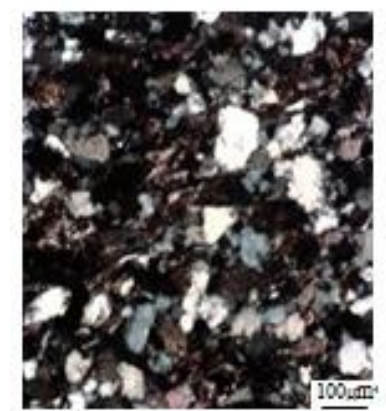

b
Fig. 1. Polari-microscope images of sandstone

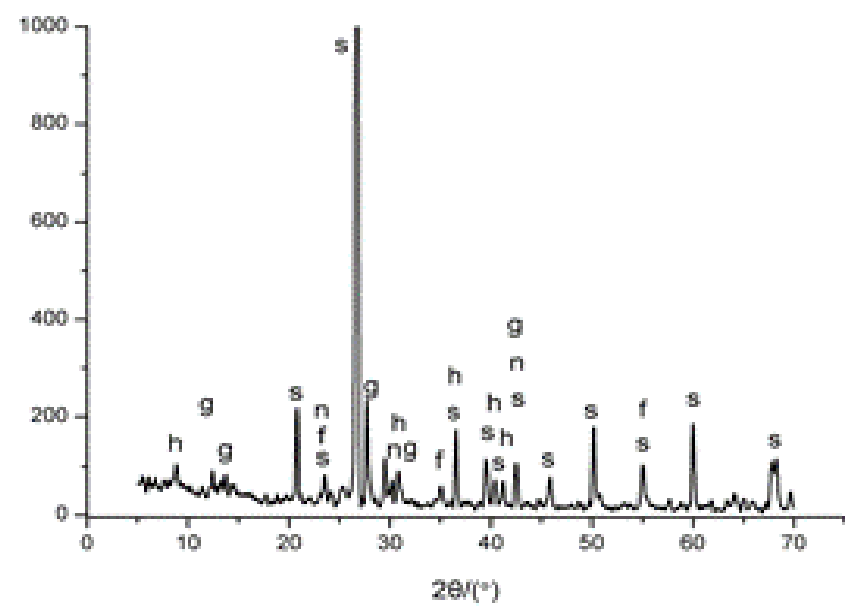

Fig. 2. X-ray diffraction patterns of sandstone, s-quartz, $\mathrm{f}$-calcite, $\mathrm{n}$-sodium, $\mathrm{h}$ - feldspar, $\mathrm{g}$ - sodium fel
As shown by the results, sandstone is a metamorphic calcareous sandstone with ablastopsammitic structure, which is made from palimpsest sand, calcite and mica.Palimpsest sand consists mainly of monocrystalline quartz and polycrystal quartz with a small amount of feldspar.

\subsection{Testing methods}

The detailed procedures of SEM analysis on sandstone aggregate were as follows: first, the rock samples were processed into particles, each with a diameter of less than $5 \mathrm{~mm}$ and were put into stainless steel containers, and $10 \mathrm{ml}$ $\mathrm{NaOH}$ solution with a concentration of $1 \mathrm{~mol} / \mathrm{L}$ was added into the test vessel, after which the cover was tightened, and the container was placed in a thermostatic-controlled water bath at $80{ }^{\circ} \mathrm{C}$. Second, the particulate samples were taken out after $3 d$ and $7 d$ of exposure. After washing with anhydrous alcohol in the crucible, the samples were dried in an oven at $60^{\circ} \mathrm{C}$.

Artificial coarse aggregate (size from $5 \mathrm{~mm}-120 \mathrm{~mm}$ ) and fine aggregate (sized at under $4.75 \mathrm{~mm}$ ) were used in this study. A rapid concrete prism test was designed on the basis of the standard concrete prism test (DL/T5150-2001, Hydraulic Concrete Test Regulations). Mixed proportions of one grade of concrete are listed in Table 2.

Two aggregate combinations (i.e., full sandstone and the combination of sandstone coarse aggregate and marble sand), at two size grades, multi-graded (sized at $5 \sim 20 \mathrm{~mm}$, and $20 \sim 40 \mathrm{~mm}$ ) and fully-graded, with a fly ash content of $35 \%$, were used for the tests. The gradation was based on the standard concrete prism test method. Also, the aggregate gradation used the mix ratio of the adjusted multi-graded and fully-graded concrete are summarized in Table 3. At prescribed ages, the resistance and resistance ratio of the strain meter were measured. The "Concrete Autogenous Volume Deformation Test" method (according to DL/T5150-2001, Hydraulic Concrete Test Regulations) was used to calculate the changes in length of the samples.

Table 1. Chemical properties of cement, fly ash and aggregate (\%)

\begin{tabular}{|c|c|c|c|c|c|c|c|c|c|}
\hline & $\mathrm{SiO}_{2}$ & $\mathrm{CaO}$ & $\mathrm{MgO}$ & $\mathrm{Fe}_{2} \mathrm{O}_{3}$ & $\mathrm{Al}_{2} \mathrm{O}_{3}$ & $\mathrm{SO}_{3}$ & $\mathrm{~K}_{2} \mathrm{O}$ & $\mathrm{Na}_{2} \mathrm{O}$ & Loss on ingition \\
\hline Cement & 21.28 & 61.75 & 3.68 & 5.54 & 4.12 & 1.67 & 0.45 & 0.12 & 1.39 \\
\hline ASR-1 & 45.86 & 13.53 & 1.15 & 0.58 & 0.79 & 0.37 & 0.58 & 0.24 & 24.47 \\
\hline ASR-2 & 32.04 & 44.76 & 2.19 & 0.71 & 2.05 & 0.07 & 0.15 & 0.17 & 17.86 \\
\hline Fly ash 1 & 52.56 & 3.24 & 1.16 & 9.51 & 24.21 & 0.37 & 1.00 & 0.27 & 3.51 \\
\hline Fly ash 2 & 52.44 & 3.20 & 1.14 & 9.44 & 24.03 & 0.36 & 1.00 & 0.28 & 4.07 \\
\hline Fly ash 3 & 58.93 & 3.24 & 1.25 & 9.67 & 21.59 & 0.13 & 1.00 & 0.11 & 0.95 \\
\hline Fly ash 4 & 58.95 & 3.24 & 1.24 & 9.60 & 21.59 & 0.14 & 0.99 & 0.11 & 0.92 \\
\hline Fly ash 5 & 45.06 & 3.65 & 0.90 & 14.38 & 25.88 & 0.99 & 1.50 & 0.92 & 3.44 \\
\hline Fly ash 6 & 49.16 & 5.70 & 0.82 & 12.29 & 21.27 & 1.36 & 1.50 & 0.48 & 4.48 \\
\hline Fly ash 7 & 54.40 & 1.33 & 1.29 & 4.16 & 26.22 & 0.20 & 2.74 & 0.44 & \\
\hline Fly ash 8 & 54.21 & 2.20 & 0.96 & 5.75 & 25.68 & 0.38 & 1.97 & 0.25 & 7.34 \\
\hline Fly ash 9 & 52.10 & 3.54 & 3.74 & 5.81 & 23.97 & 0.28 & 3.75 & 0.20 & 4.54 \\
\hline Fly ash 10 & 50.35 & 7.20 & 3.18 & 7.09 & 25.81 & 0.38 & 1.43 & 1.79 & 0.66 \\
\hline Fly ash 11 & 42.49 & 11.8 & 0.82 & 6.48 & 31.5 & 0.67 & 1.38 & 0.92 & 1.59 \\
\hline JPS-1 & 67.95 & 8.87 & 1.90 & 2.89 & 5.45 & 0.22 & 0.90 & 1.36 & 9.67 \\
\hline JPS-2 & 67.09 & 8.65 & 1.88 & 3.26 & 6.83 & 0.17 & 1.38 & 1.06 & 8.86 \\
\hline JPS-3 & 67.60 & 8.18 & 1.90 & 2.87 & 6.52 & 0.21 & 1.23 & 1.39 & 9.36 \\
\hline
\end{tabular}


Table 2. Mix proportions of concrete (two, multi and fully-graded)

\begin{tabular}{|c|c|c|c|c|c|c|c|}
\hline W/C & $\begin{array}{c}\text { Cement, } \\
\mathrm{kg} / \mathrm{m}^{3}\end{array}$ & $\begin{array}{c}\text { Water, } \\
\mathrm{kg} / \mathrm{m}^{3}\end{array}$ & Sand, $\mathrm{kg} / \mathrm{m}^{3}$ & Gradation & \multicolumn{3}{|c|}{ Coarse aggregate, $\mathrm{kg} / \mathrm{m}^{3}$} \\
\hline 0.43 & 420 & 181 & 720 & one & $360-15 \mathrm{~mm}$ & $15-10 \mathrm{~mm}$ & $10-5 \mathrm{~mm}$ \\
\hline
\end{tabular}

Table 3. Mix proportions of concrete (two, multi and fully-graded)

\begin{tabular}{|c|c|c|c|c|c|c|c|c|}
\hline \multirow{2}{*}{$\mathrm{W} / \mathrm{C}$} & \multirow{2}{*}{ Cement, $\mathrm{kg} / \mathrm{m}^{3}$} & \multirow{2}{*}{ Water, $\mathrm{g} / \mathrm{m}^{3}$} & \multirow{2}{*}{ Sand, $\mathrm{kg} / \mathrm{m}^{3}$} & \multirow{2}{*}{ Gradation } & \multicolumn{4}{|c|}{ Coarse aggregate, $\mathrm{kg} / \mathrm{m}^{3}$} \\
\hline & & & & & $20-5 \mathrm{~mm}$ & $40-20 \mathrm{~mm}$ & $80-40 \mathrm{~mm}$ & $120-80 \mathrm{~mm}$ \\
\hline \multirow{3}{*}{0.43} & \multirow{3}{*}{420} & \multirow{3}{*}{181} & \multirow{3}{*}{720} & 2 & 540 & 540 & - & - \\
\hline & & & & 3 & 270 & 270 & 540 & - \\
\hline & & & & 4 & 216 & 216 & 270 & 378 \\
\hline
\end{tabular}

\section{RESULTS AND DISCUSSION}

\subsection{SEM analysis}

The use of granite or sandstone aggregates in the United States, France, and India has caused the destruction of alkali-aggregate reactions. At the present time, there is no consensus on the cause of the alkali activity of granite. It has been inferred that the phenomenon is related to deformed quartz, as pointed out in the Engineer Manual of the US Army Corps of Engineers (1983). It is suggested that aggregates can be considered as being potential active when the extinction angle of deformed quartz glass is above $25^{\circ}$, and the content of deformed quartz is greater than $25 \%$.

The application of SEM examination methods to elucidate the reaction of alkali-aggregate in concrete and its expansion mechanism is of great significance for understanding the reaction products of alkali-aggregates, the degradation mechanism of concrete subjected to the reaction of alkali-silica, and the study of the initiation process of the swelling source $[19,20]$.

In order to check whether the sandstone in this study was active, sandstone protolith and sandstone soaked in alkali solution were examined under SEM. SEM images of the sandstone protolith are presented in Fig. 3. The sandstone was soaked in $\mathrm{NaOH}$ solution for $3 \mathrm{~d}$ and $7 \mathrm{~d}$. As shown in Fig. 3, the sandstone protolith exhibits a dense structure and a clear joint.

The petaloid substance was uniformly distributed, with a soft structure on the surface of the samples soaked in $\mathrm{NaOH}$ solution for $3 \mathrm{~d}$. The Petaloid substance was $\mathrm{Na}(\mathrm{K})-$ $\mathrm{Si}-\mathrm{H}$ gel,the accumulation and expansion of which results in uneven expansion and cracking along the interface in concrete.

$\mathrm{Na}^{+}\left(\mathrm{K}^{+}\right)+\mathrm{SiO}_{2}+\mathrm{OH}-\rightarrow \mathrm{Na}(\mathrm{K})-\mathrm{Si}-\mathrm{H}$ gel

Samples that had been soaked in $\mathrm{NaOH}$ for 7 days exhibited a growing amount of petaloid substance on the surface. If a comparison of results from Fig. $3 \mathrm{a}$ and $\mathrm{c}$ is taken, there are reaction products $(\mathrm{Na}-\mathrm{Si}-\mathrm{H}$ gel) of ASR in Fig. 3 c, which confirms that ASR took place. Also, as the reaction time increased, the products of the reaction on the sandstone surface increased in number and the morphology of the products changed.The mesoscopic phenomenon further verified that silica stone had ASR reactivity.

\subsection{Fast concrete prism test}

The rapid concrete prismatic method is a test method in the RILEM Standard from the International Federation of
Materials and Building Structures Research Institute, which enables the alkali activity of aggregates and the safety of ASR to be assessed for specific concrete mixes.

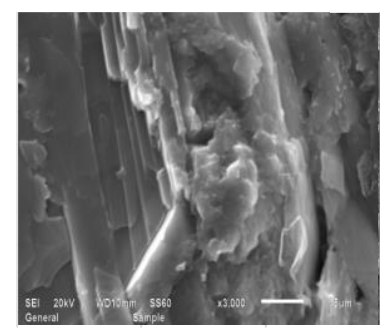

a

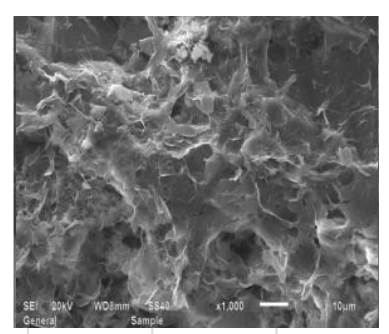

b

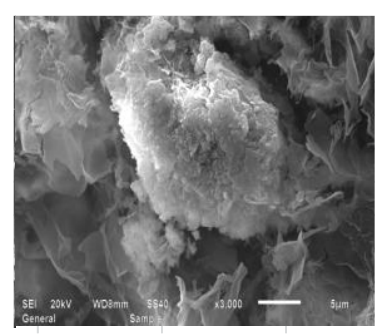

c

Fig. 3. SEM images of sandstone: $a$ - original sample; $b$-sample soaked 3d; c-sample soaked 7d

The method uses an expansion rate of $0.02 \%$ of the test specimen volume at the age of three months as the acceptance criterion. According to this criterion, test results are obtained that are more in line with actual in-service behavior. For some important projects, in order to ensure the long-term safety of the concrete, the reaction time can be prolonged to 6 months when this method is used to detect expansion.

For some important projects, in order to ensure the longterm safety of the concrete, the reaction time can be prolonged to 6 months when this method is used to detect expansion. The expansion rate threshold criterion is still $0.02 \%$ and the expansion curve should be close to a horizontal straight line. 


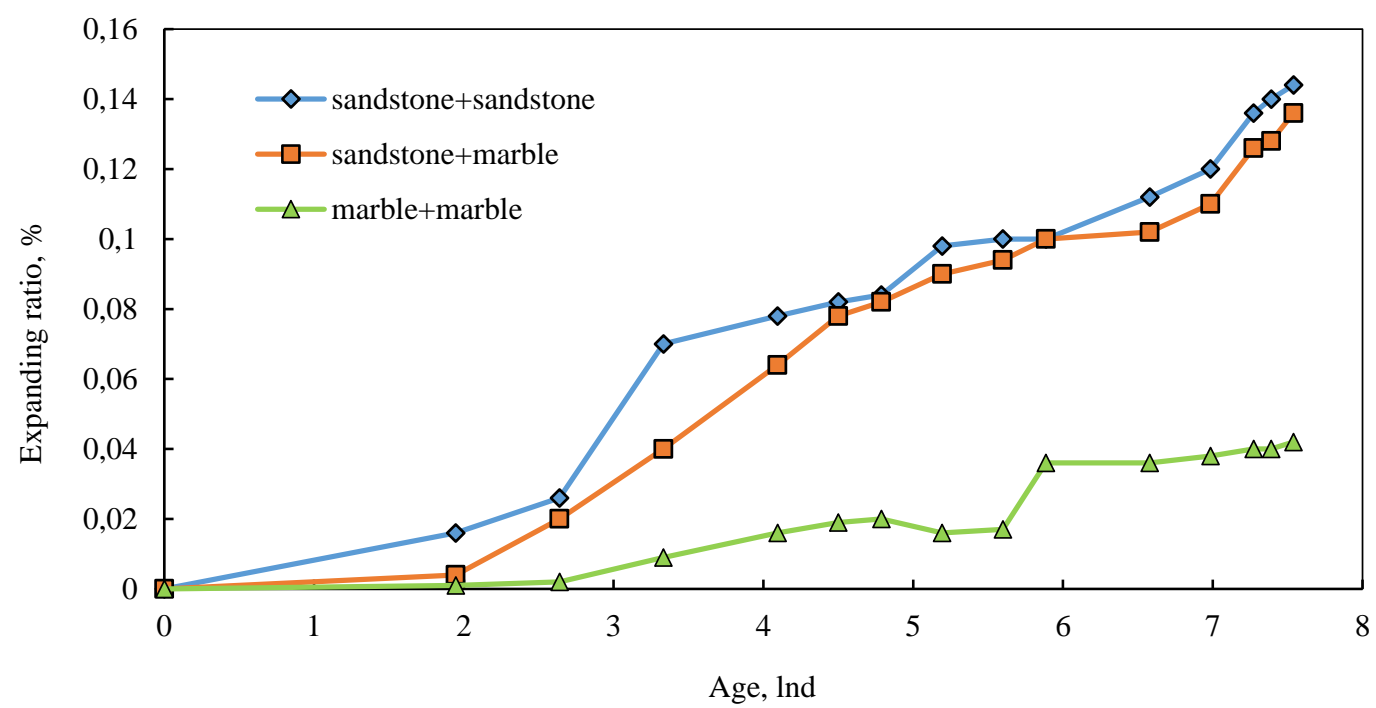

Fig. 4. Results of fast concrete prism test, $60^{\circ} \mathrm{C}$ curing

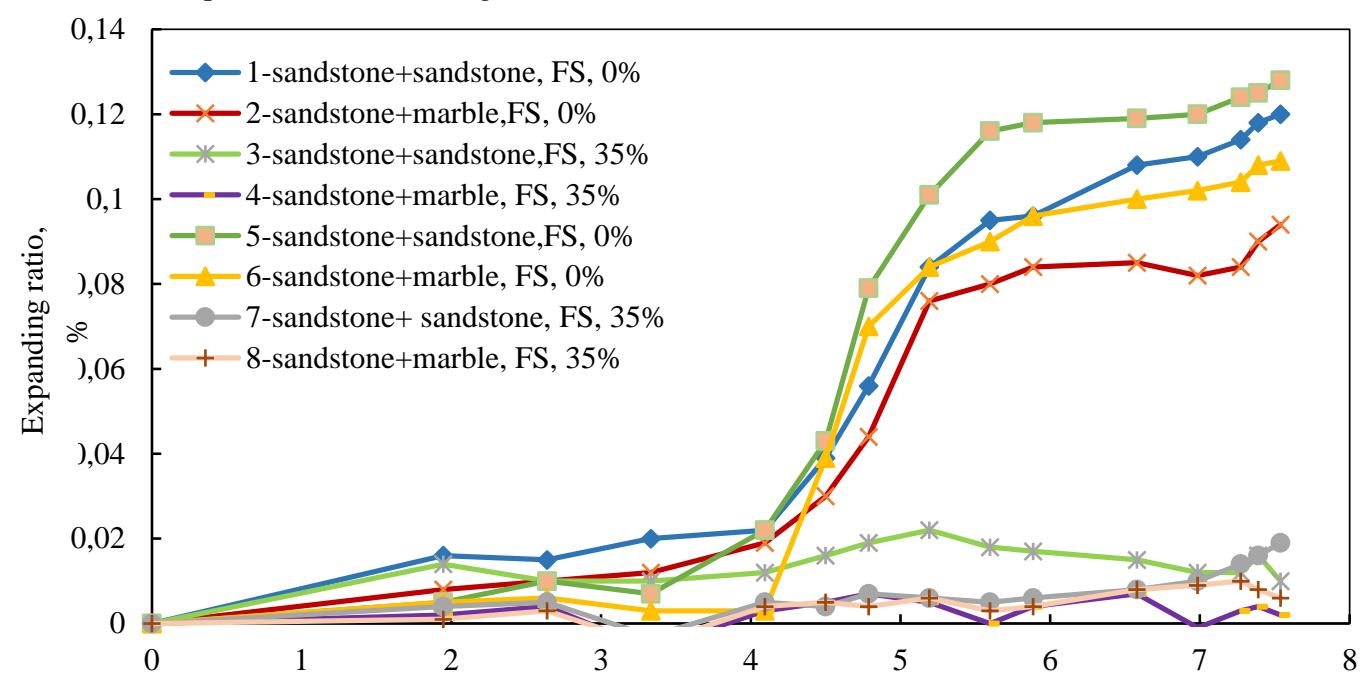

Fig. 5. Expanding ratios of concrete prism test method, $100 \mathrm{~mm} \times 100 \mathrm{~mm} \times 400 \mathrm{~mm}$ one gradation and two gradations

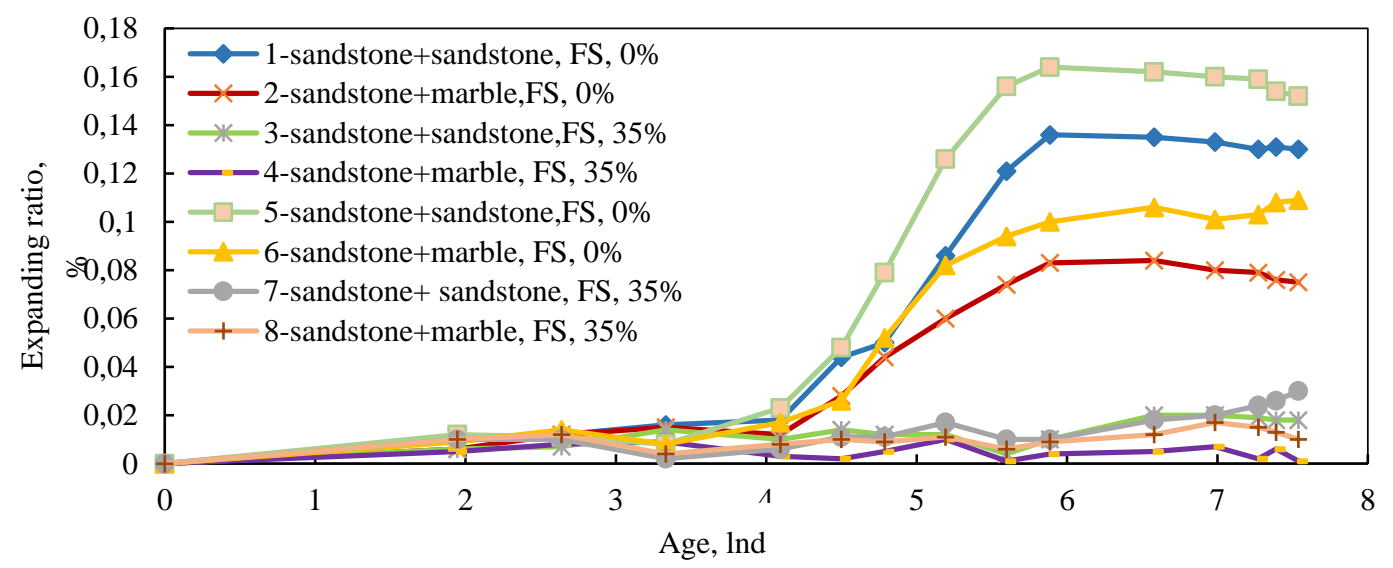

Fig. 6. Expanding ratios of concrete prism test

The actual concrete environment sometimes can be more severe. For this purpose, the alkali content of the concrete can be increased, or the specimen can be cured in an alkaline solution, to enable the ASR safety of the aggregate and the concrete to be evaluated. Because the fast concrete prismatic method is a trial method, the final parameters, test procedures, and the determination of the acceptance criteria also need to be cross-tested and verified by various laboratories for a variety of aggregates and concrete ratios, and knowledge of concrete expansion behavior should be continuously improved. When the aggregate was combined with a coarse aggregate of silica, 
ASR activity was evident.However, in samples that combined the aggregate coarse and fine aggregates from marble, ASR was not active, as is illustrated in Fig. 4. Also, concrete prism test samples made from a combination of sandstone aggregate under a reservation of $60{ }^{\circ} \mathrm{C}$ exhibited growth in expansion with extended exposure time. Additionally, samples that included pure marble samples showed similar expansion growth. In some of these samples, the overall expansionexceeded the threshold value of $0.04 \%$, though it only had a mild growth rate.

The composite aggregate with sandstone alone experienced greater expansion than did the mixture of sandstone and marble, which indicated that replacing sandstone sand with marble sand reduced the degree of expansion. Also, artificial marble sand with different modes of fineness did not have a major effect on the expansion of the concrete prism test samples, as shown in Fig. 5. Concrete samples with different combinations of aggregate expanded more as time went on under high alkali conditions. Therefore, the alkali content of concrete should be strictly limited.

As shown in Fig. 6, for concrete with different gradation, and for the two aggregate combinations without fly ash doping, expansion increased with age, and the expansion of the full-sandstone aggregates was greater than that of the composite aggregates of sandstone and marble. When the fly ash content reached $35 \%$, the expansion of the concrete prism test samples was below $0.02 \%$. Over a period of five years, that becomes an expansion reduction of over $80 \%$. Furthermore, the change in expansion of the composite aggregate of sandstone and marble at a five-year age was as small as that of the one-year aged sample, and both had expanded less than $0.01 \%$.

When activated silica in the fly ash was crushed into particles and was mixed thoroughly in each part of the concrete system, it transformed the limited parts into unlimited active centers. Each center participating in the reaction consumed alkali. As a result, energy can only scatter and is incapable of local concentration. Therefore, the energy is resolved, inhibiting the alkali-aggregate reaction. The results showed that a fly ash mass content of $35 \%$ greatly inhibited the reactivity of sandstone aggregate. With an increase in the paste/aggregate ratio, the expansion of the concrete prism test samples increased accordingly.

\subsection{SEM analysis of concrete samples}

In order to analyse the alkali activity of samples taken from a standard maintenance at $38{ }^{\circ} \mathrm{C}$ with two types of aggregates and two types of concrete grading, a test block was made, under the condition of minimum crushing vibration, with a relatively flat and intact interface, and was prepared under vacuum with gold plating on its surface for SEM examination.

For the two aggregate combinations (full sandstone and the combination of sandstone coarse aggregate and marble sand) and the two aggregate gradations (multi-graded and fully-graded), an SEM examination was conducted to evaluate the degree of the alkali reaction in the samples with fly ash contents of $35 \%$.

Several conclusions were drawn from the micromorphology displayed in Fig. 7. First, for the multi-graded and full-grade concrete samples molded from full sandstone aggregate, soft, small conchoidal or cottony reaction products (Na-Si-H gel) clearly could be observed. Second, for the multi-graded and full-grade concrete samples molded from the composite aggregate of marble and sandstone-aggregate, a small number of alkali-aggregate reaction products could be found locally. Of these products, the majority were long-cylindrical or slender-cylindrical cement hydration products that were closely stacked. Third, the full sandstone aggregate-molded concrete samples generated more alkali-aggregate reaction products than did the samples molded from composite aggregates of sandstone and marble, and the former exhibited more intense reaction.

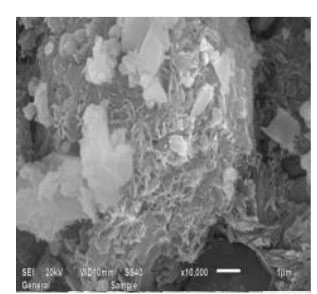

a

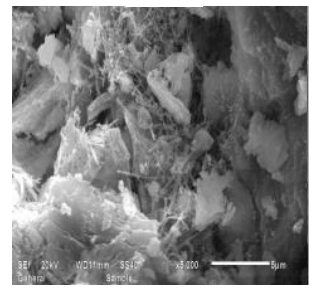

c

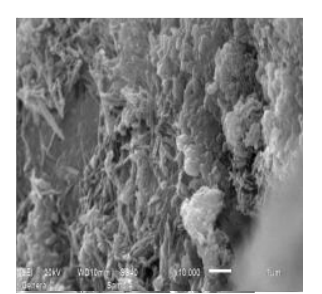

b

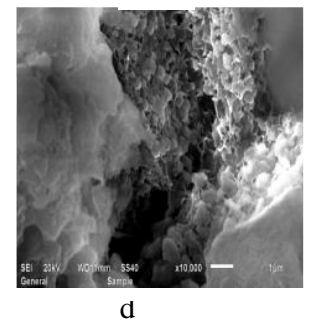

Fig. 7. SEM images of a five-year concrete prism specimen: $\mathrm{a}$-sandstone two gradation; $\mathrm{b}$-sandstone+marble two gradation; $\quad \mathrm{c}$-sandstone fully-graded; d-sandstone+marblefully-graded

\subsection{Quality control index of fly ash}

From the results of former tests, an objective and reliable quality evaluation model for the influence of fly ash in a concrete mixture can be developed in order to derive a fly ash control index for inhibition of the alkali-aggregate reaction. Additionally, the $\mathrm{CaO}$ content, alkali content and $\mathrm{SiO}_{2}+\mathrm{Al}_{2} \mathrm{O}_{3}+\mathrm{Fe}_{2} \mathrm{O}_{3}$ contents were found to be poor indicators of the control index of fly ash in the alkaliaggregate reaction. According to the literature [2-7], the inhibition effects of fly ash on the alkali-aggregate reaction were inferred by observing the value of $\mathrm{C}_{\mathrm{fa}}$. The basic form of $\mathrm{C}_{\mathrm{fa}}$ is:

$\mathrm{C}_{\mathrm{fa}}=\frac{\mathrm{CaO}+\mathrm{X}_{1} \mathrm{R}_{2} \mathrm{O}+\mathrm{X}_{2} \mathrm{MgO}+\mathrm{X}_{3} \mathrm{SO}_{3}}{\mathrm{X}_{4} \mathrm{SiO}_{2}+\mathrm{X}_{5} \mathrm{Al}_{2} \mathrm{O}_{3}+\mathrm{X}_{6} \mathrm{Fe}_{2} \mathrm{O}_{3}}$

The relationship between the chemical factor and the expansion ratios of a 28-day mortar bar and 1-year concrete prism specimens mixed with $35 \%$ fly ash are shown in Fig. 8 and Fig. 9, respectively. The chemical factor, which was calculated by the expression of the chemical composition factor of fly ash, has a good correlation with the expansion ratios of the $28 \mathrm{~d}$ mortar bar and 1-year concrete prism specimens. Although the expansion ratios of 
the $28 \mathrm{~d}$ mortar bar and 1-year concrete prism specimens were not identical to the chemical composition factor of fly ash, the two factors were related. The results showed that using the chemical composition factor for the fly ash, calculated using the above expression to measure the quality of fly ash, was a viable method of predicting likely concrete expansion behavior.

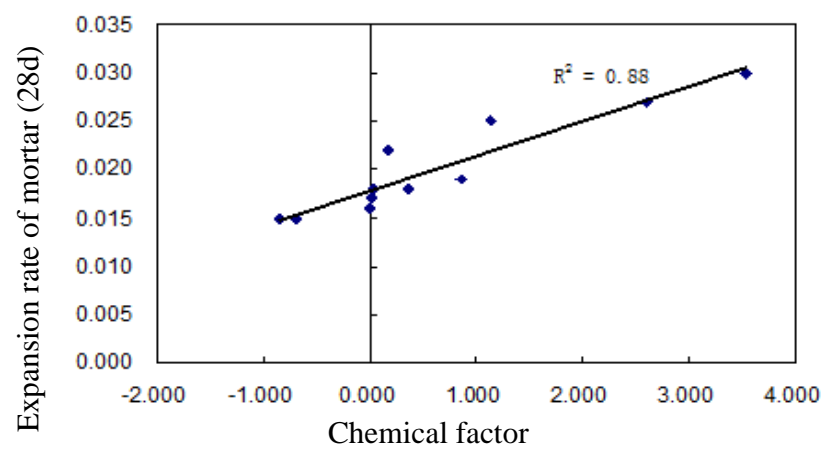

Fig. 8. Relationship between fly ash and chemical factors in 28d, accelerated mortar-bar test

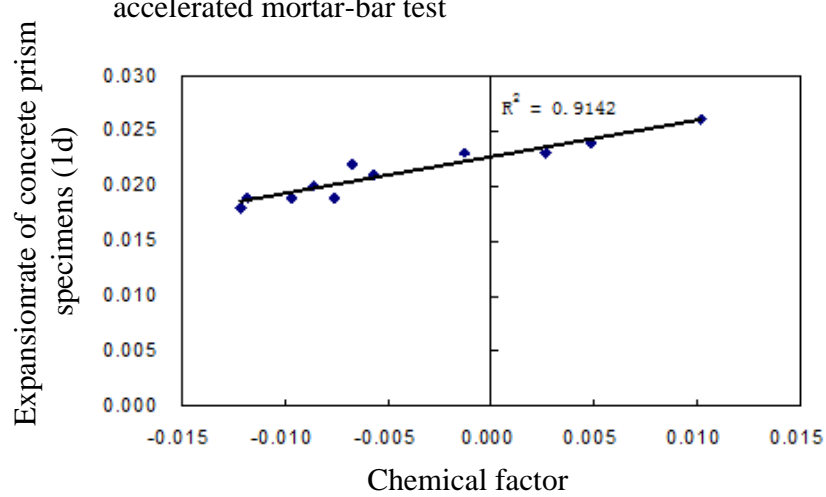

Fig. 9. Relationship between fly ash and chemical factors in 365d, concrete prism test method

The following will verify its reliability through domestic and foreign research results.

1. Verification of test results of Nanjing Hydraulic

Research Institute

Nanjing Hydraulic Research Institute did a series of studies on the effect of chemical composition of fly ash on the inhibition of alkaline activity of the aggregate. Adoptingthe rapidmethod of mortar bar, 42.5 Ordinary Portland Cement of Nanjing Conch, and the cement alkali content was adjusted to $1.0 \%$. The amount of fly ash was $20 \%$ of the total cementitious material, and the aggregate was a natural river sand in Nanjing. The $\mathrm{CaO}$ content of 11 types of tested fly ash are from $1.93 \%$ to $11.64 \%$, the equivalent alkali content from $0.49 \%$ to $2.48 \%$. Calculate the chemical composition of fly ash obtained from this study and calculate the experimental data of the South Institute of Science. The relationship between the fly ash chemical factor and the expansion rate of the mortar rod $14 \mathrm{~d}$ is shown in Fig. 10.

2. Verification of test results of Shehata and Thomas

Shehata and Thomas studied the influence of the chemical composition of fly ash on their alkali aggregates in 1997 [10]. Adopting the concrete prismatic method, the amount of fly ash was $25 \%$. The $\mathrm{CaO}$ content of 11 types of tested fly ash between $5.57 \%$ to $30.0 \%$ with equivalent alkali content are from $0.30 \%$ to $4.79 \%$. The test data come from Shehata and Thomas were calculated by using the fly ash chemical factor expression obtained in this study. The relationship between the fly ash chemical factor and the two-year expansion rate of the concrete prism is shown in Fig. 11.

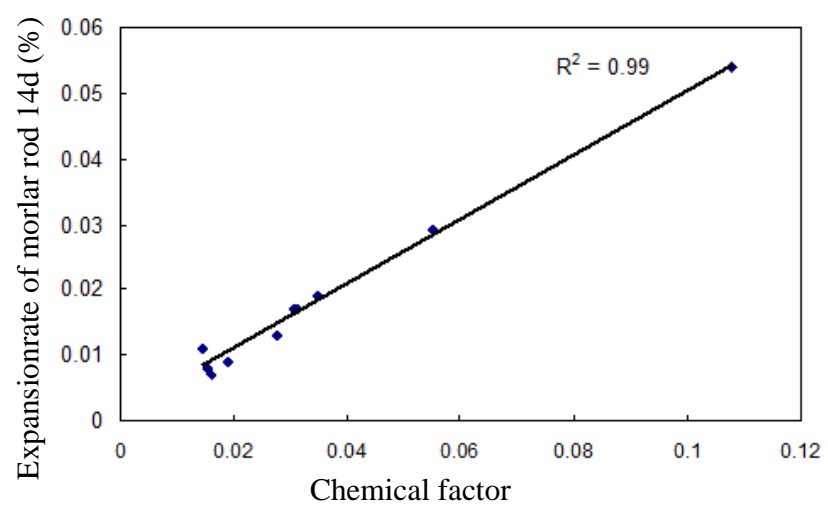

Fig. 10. Relationship between expansion rate of slurry rod at $14 \mathrm{~d}$

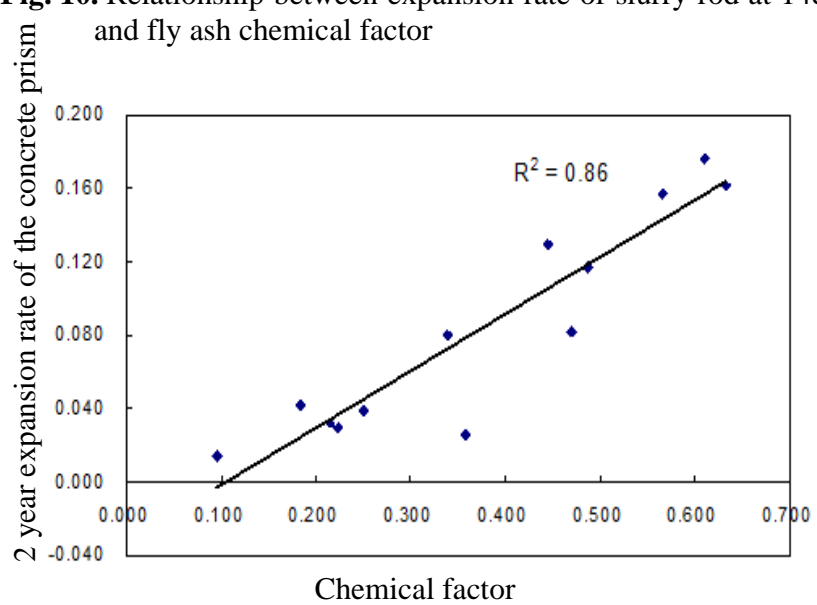

Fig 11 Relationship between the fly ash chemical factor and the two-year expansion rate of the concrete prism

From the above test of verification literature, we can see that although they use different test methods (fast mortar bar and concrete prism method), different fly ash content (the amount of $20 \%$ and $25 \%$, respectively), the relationship between the chemical composition of the fly ash and the non-linear regression analysis of the chemical composition factor and the expansion rate are still basically linear. The correlation coefficient $\mathrm{R}_{2}$ is 0.99 and 0.86 , respectively, indicating that the chemical composition factor can better reflect the effect of fly ash in inhibiting the reaction of alkali aggregates. However, it also shows that the chemical composition of fly ash is related to the cement type, the amount of fly ash, the type of aggregate, and the method for evaluating the inhibitory effect.

\subsection{Two inhibition materials on ASR}

\subsubsection{Metakaolin and composited powder}

The inhibitory effect of metakaolin on concrete ASR has been confirmed by many researchers. In order to develop better materials for inhibiting ASR, several new materials were chosen in order to get better inhibition effects. Metakaolin and composited powder were used as two kinds of inhibition materials (identified as 'ASR-1' and 
'ASR-2') that would reduce the ASR. Addition ratios of 5\%, $10 \%$, and $15 \%$ were chosen for this study. ASR inhibition was greatest when the content of ASR-1 was $15 \%$, and as the content increased, the expansion rate decreased, as is shown in Fig. 12. As for ASR-2, the expansion rate decreased slightly but the inhibition effect was not significant when the content was under $15 \%$.

\subsubsection{Limestone powder inhibition test}

A recent study has shown that active aggregate mixed with a certain amount alkaliaggregate had an effect on the alkali-aggregate reaction [19]. Therefore, this test combined with the test of active sandstone powder and inactive marble stone powder to restrain the activity of the alkali effect. Fig. 13 and Fig. 14 show the accelerated mortar-bar test results using Emei cement and sand aggregates with different replacement contents, i.e., $10 \%, 15 \%, 20 \%$, and $25 \%$.

The expansion rate of the mortal bars was slightly lower with different proportional replacements of cement or aggregate with active sandstone powder and inactive marble stone powder. The inhibitory effect was not obvious in the content range up to $25 \%$. Under the same conditions, the expansion rate reduction value was higher than that of cement that contained only the inactive marble stone powder.

\subsection{Long-term alkali activity simulation of fully- graded concrete}

At present, ASR tests and suppression methods "have only been used for shorted time periods. and no more longterm results can be seen. Based on this new fully-graded concrete, observations have been made in the present study for up to five years and it is expected that, in the future, more reliable relationships and better supplements will be identified, compared to the materials used when obtaining the early evaluation results. Four groups of specimens with fully-graded long-term test mixing ratios were studied after standard curing at $20^{\circ} \mathrm{C}$, and after outdoor natural curing conditions for approximately 5 years.

The results, as shown in Fig. 15, the expansion rate of the concrete specimens that underwent standard curing at $20{ }^{\circ} \mathrm{C}$ was higher than those of the specimens that had the same aggregate combination conditions but were cured under outdoor natural conditions.
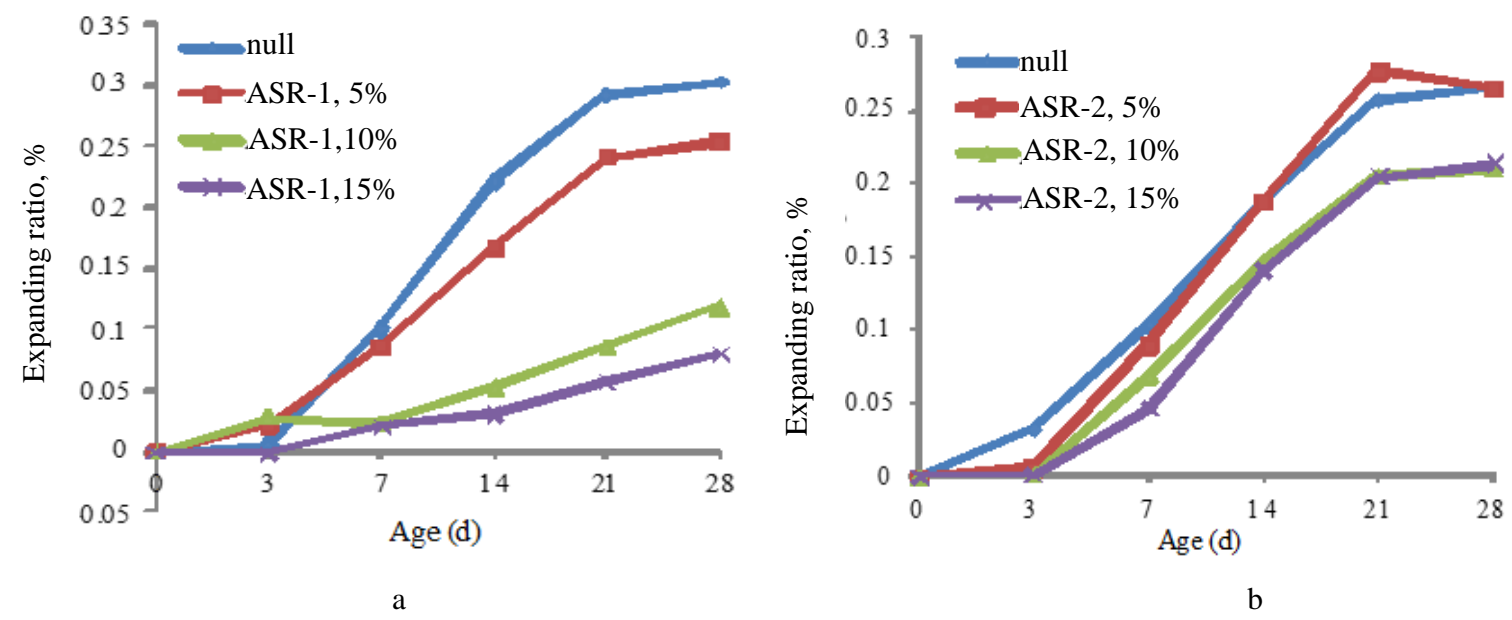

Fig. 12. Accelerated mortar-bar test results of inhibition materials on ASR: $a$-sandstone; $b$-marble
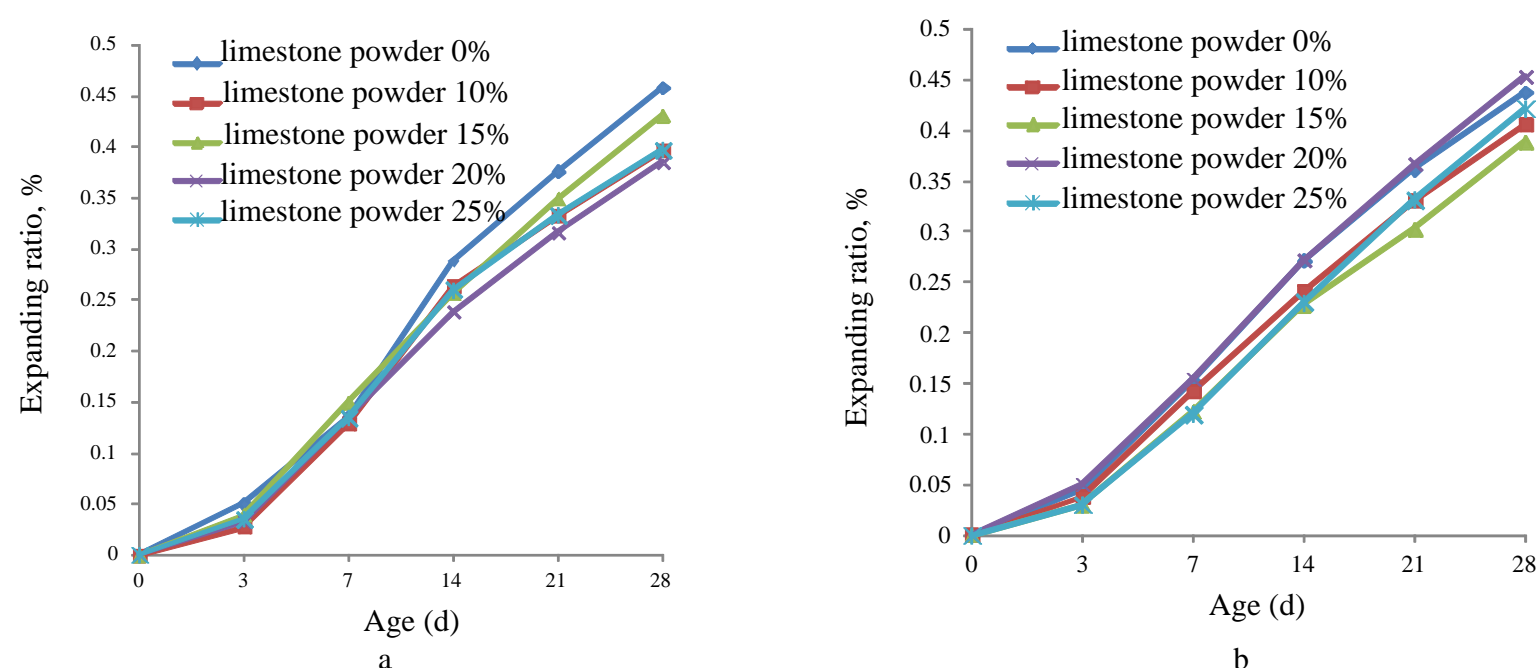

Fig.13 Accelerated mortar-bar test results of limestone powder instead of cement on ASR inhibition: $a$-sandstone; $b$ - marble 


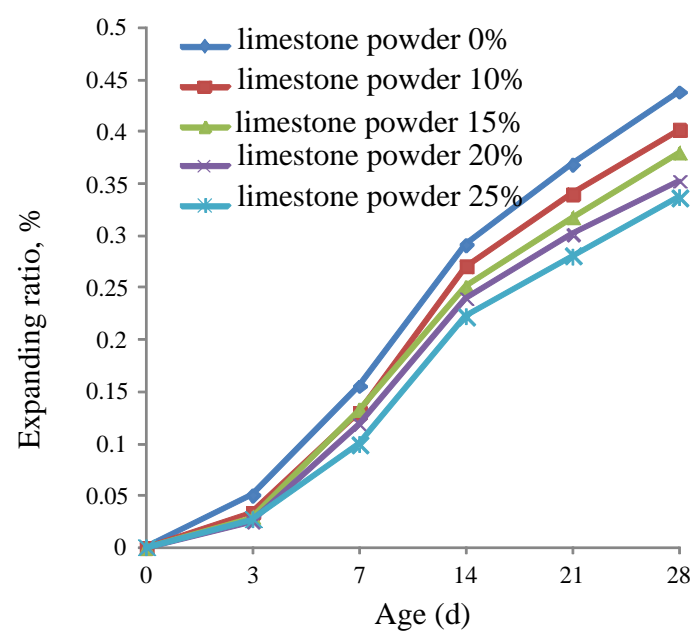

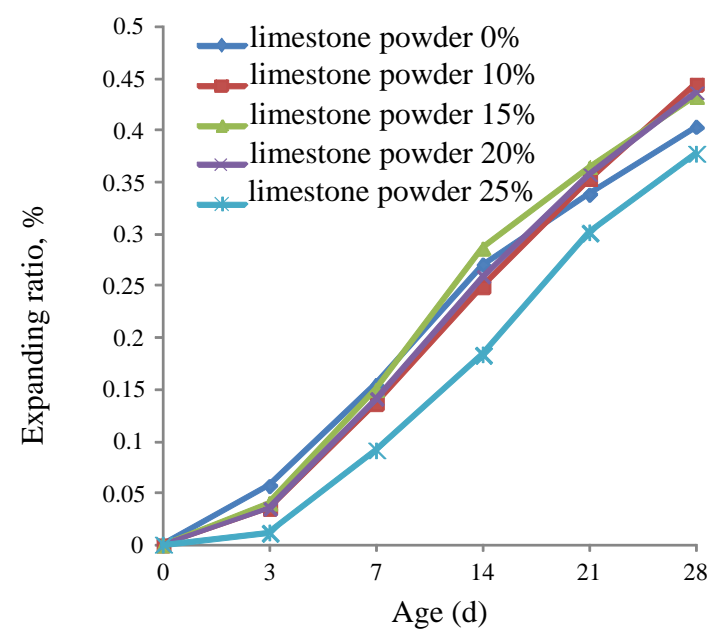

b

Fig. 14. Accelerated mortar-bar test results of limestone powder instead of aggregate on ASR inhibition: $a-$ sandstone; $b-$ marble

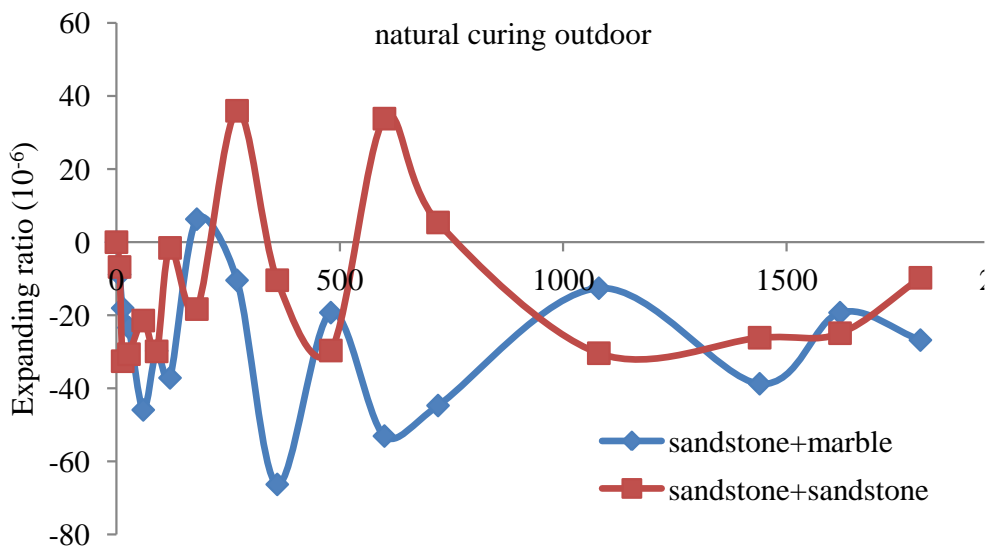

Age (d)

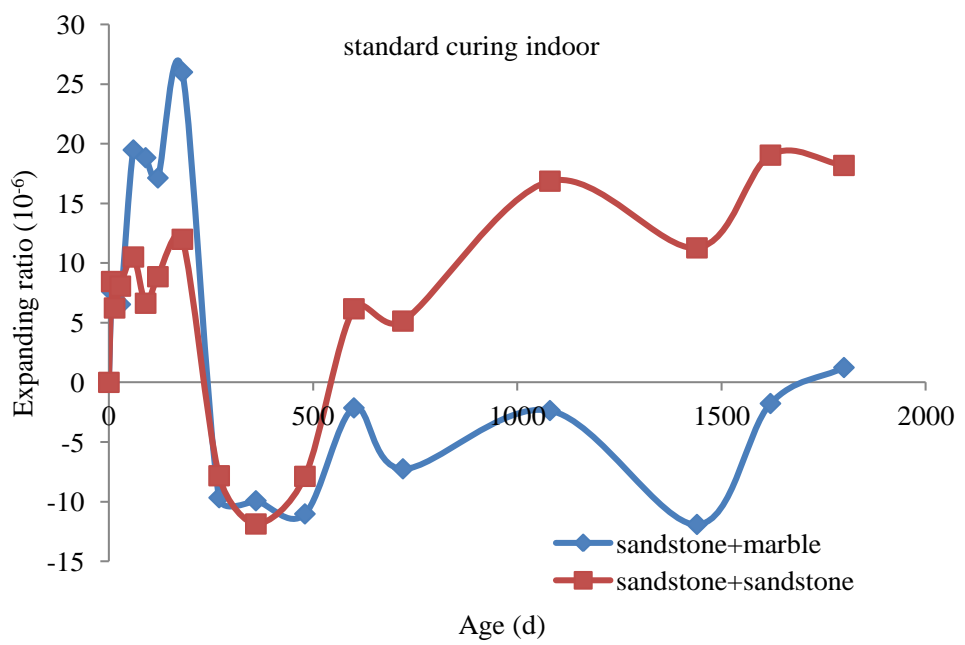

Fig. 15. Specimen expansion curves of two kinds of aggregate combination in different curing condition

The expansion rate of concrete specimens under standard curing at $20^{\circ} \mathrm{C}$ increased as the age of the concrete increased. Although the expansion rate of the concrete specimens was not dramatically affected by outdoor natural curing, the outdoor temperature and humidity seemed to be relevant in affecting the degree of long-term expansion.
The concrete specimen expansion rate of full sandstone was slightly higher than the expansion rates of sandstone and marble mixed specimens under the same curing conditions. Although change in the expansion rate of the concrete specimens under outdoor natural curing was irregular, the volume changes of sandstone and marble 
mixed specimens was essentially negative, while the volume change of full sandstone varied between positive and negative values.

\section{CONCLUSIONS}

The influence of different aggregate combinations and inhibition materials on the ASR in fully-graded concrete, and a long-term alkali activity simulation of fully-graded concrete, were investigated in this study. Additionally, eleven kinds of fly ash were used to investigate the influence of chemical composition factors on the ASR and to measure the quality of the fly ash. The results were as follows:

1. Full sandstone, fully-graded concrete specimens had higher expansion rates than did the specimens that contained marble stone. The new inhibition materials produced a noticeable inhibitory effect on the sandstone aggregate alkali activity. The concrete specimen expansion rate after standard curing at $20^{\circ} \mathrm{C}$ was higher than was that of samples that underwent outdoor natural curing. The full sandstone concrete specimens had higher expansion rates than did the specimens that contained marble stone.

2. SEM examination to assess long-term concrete alkali activity behavior can assist in the observation of characteristic reaction products at the alkali-aggregate interface during the active alkali-aggregate reaction. This can improve qualitative understanding of the extent of the alkali-aggregate reaction and also assist in the prediction of the concrete deterioration trend.

3. The replacement of artificial sandstone sand with artificial marble sand can reduce the alkali activity expansion rate of sandstone aggregate and can improve significantly the inhibition effect of aggregate mixed with $35 \%$ fly ash. Use of the chemical composition factor of fly ash, calculated by the expression to measure its quality, is a viable method that will merit future research.

\section{Acknowledgments}

This project is funded by The Natural Science Foundation of China (No.51539002, N0.51709209), China Postdoctoral Science Foundation (No. 2017M622541).

\section{REFERENCES}

1. Malvar, L.J., Lenke, L.R. Efficiency of Fly Ash in Mitigating Alkali-silica Reaction Based on Chemical Composition ACI Materials Journal 103 (5) 2006: pp. 319-326.

2. American Society of Testing and Materials. Standard Guide for Petrographic Examination of Aggregates for Concrete.ASTM C295-03 Annual Book of ASTM Standards 04.022003.

3. American Society of Testing and Materials. Standard Test Method for Effectiveness of Pozzolans or Ground BlastFurnace Sla in Preventing Excessive Expansion of Concrete Due to Alkali-Silica Reaction. ASTM C441-02a Annual Book of ASTM Standards 04.022003.

4. Lee, N. Alkali-Silica Reactivity in Concrete, Branz Ltd., New Zealand, 2005: pp. 15-16.

5. Ponce, J.M., Batic, O.R. Different Manifestations of the Alkali-silica Reaction in Concrete According to the Reaction
Kinetics of the Reactive Aggregate Cement \& Concrete Research 36 (6) 2006: pp. $1148-1156$.

6. Marzouk, H., Langdon, S. The Effect of Alkali-aggregate Reactivity on the Mechanical Properties of High and Normal Strength Concrete Cement \& Concrete Composites 25 2003: pp. 549-556. https://doi.org/10.1016/S0958-9465(02)00094-X

7. García-Lodeiro, I., Palomo, A., Fernández-Jiménez, A. Alkali-Aggregate Reactionin Activated Fly Ash Systems Cement \& Concrete Research 37 (2) 2007: pp. 175-183. https://doi.org/10.1016/j.cemconres.2006.11.002

8. Shehata, M.H., Thomas, M.D.A. The Effect of Fly Ash Composition on the Expansion of Concrete due to Alkali Silica Reaction Cement and Concrete Research 30 2000: pp. $1063-1072$. https://doi.org/10.1016/S0008-8846(00)00283-0

9. Thomas, M.D.A., Shehata, M.H., Sashiprakash, S.G., Hopkins, D.S., Cail, K. Use of Ternary Cementitious Systems Containing Silica Fume and Fly Ash in Concrete Cement \& Concrete Research 29 1999: pp. 1207-1214. https://doi.org/10.1016/S0008-8846(99)00096-4

10. Moisson, M., Cyr, M., Ringot, E., Carles-Gibergues, A. Efficiency of Reactive Aggregate Powder in Controlling the Expansion of Concrete Affected by Alkali-silica Reaction (ASR) In: Proceedings of the 12th International Conference on Alkali-Aggregate Reaction in Concrete 2004: pp. 617-624.

11. Dähna, R., Arakcheevab, A., Schauba, P. Application of Micro X-ray Diffraction to Investigate the Reaction Products Formed by the Alkali-silica Reaction in Concrete Structures Cement and Concrete Research 79 2016: pp. 49-56. http://dx.doi.org/10.1016/j.cemconres.2015.07.012

12. Schumacher, K.A., Ideker, J.H. New Considerations in Predicting Mitigation of Alkali-Silica Reaction Based on Fly Ash Chemistry Journal of Materials in Civil Engineering 27 (4) 2015: pp. 1-10. http://dx.doi.org/10.1061/(ASCE)MT.1943-5533.0001021

13. Liu, S.H., Bracci, J.M., Mander, J.B., Hurlebaus, S. Performance of D-Regions Affected by Alkali-Silica Reaction: Accelerated Exposure and Damage ACI Materials Journal 4 (112) 2015: pp. 501-511. http://dx.doi.org/10.14359/51687752

14. Poyet, S., Sellier, A., Capra, B. Influence of Water on Alkali-Silica Reaction: Experimental Study and Numerical Simulations Journal of Materials in Civil Engineering 18 (4) 2014: pp. $588-596$. http://dx.doi.org/10.1061/(asce)0899-1561(2006)18:4(588)

15. Zhou, Q., Li, G. Experimental Study on Suppressing of Alkali-silica Reaction by Phosphorus Slag Advances in Science and Technology of Water Resources 28 (2) 2008: pp. 39-41.

16. Ding, J., Bai, Y., Cai, Y. Suppressing effect of Lithium Slag on Alkali-silica Reaction and Separation of its Self-expansion Journal of Hohai University (Natural Sciences) 36 (6) 2008: pp. 824-827. http://dx.doi.org/10.3901/JME.2008.05.160

17. Bajja, Z., Dridi, W., Darquennes, A., Bennacer, R., Bescop, Le.P. Effect of Aggregates on the Diffusion Properties and Microstructure of Cement with Slurried Silica Fume Based Materials Cement and Concrete Composites 70 2016: pp. 86-97. http://dx.doi.org/10.1016/j.cemconcomp.2016.03.004

18. Rao, M., Yang, H., Lin, Y., Li, J., Shi, Y. Influence of Maximum Aggregate Sizes on the Performance of RCC Construction and Building Materials 115 2016: pp. 42-47. 
http://dx.doi.org/10.1016/j.conbuildmat.2016.03.172

19. Jan, L., Michael, T., Erik, S. Alkali-silica Reaction (ASR)Performance Testing: Influence of Specimen Pre-treatment, Exposure Conditions and Prism Size on Alkali Leaching and Prism Expansion Cement and Concrete Research 53 (11) 2013: pp. $68-90$

http://dx.doi.org/10.1016/j.cemconres.2013.05.017
20. Sims, I., Nixon, P., Marion, A. International Collabortion to Control Alkali-Aggregate Reaction: The successful Pragrass of RILEM TC 106 and TC 191-ARP[C] Proceedings of the 12th International Conference on Alkali-Aggregate Reaction in Concrete 2004: pp. 41-50.

http://dx.doi.org/10.1007/s12149-013-0782-9 